\title{
Correction to: The impact of nutritional counseling on thyroid disorders in head and neck cancer patients after (chemo)radiotherapy: results from a prospective interventional trial
}

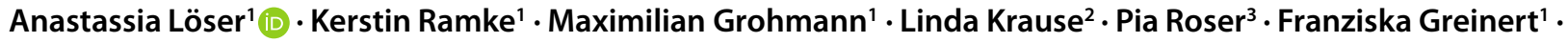 \\ Anna Finger ${ }^{1}$ - Margaret Sommer ${ }^{1}$ Eva Culmann ${ }^{1}$ - Tessa Lorenz ${ }^{1}$ Saskia Becker ${ }^{1}$. Marvin Henze ${ }^{1}$. \\ Daniel Schodrok ${ }^{1} \cdot$ Julia von Grundherr ${ }^{4} \cdot$ Silke Tribius $^{5}$ • Andreas Krüll1,6 • Cordula Petersen ${ }^{1,6}$
}

Published online: 9 December 2021

(c) The Author(s) 2021

\section{Correction to:}

\section{Strahlenther Onkol 2021}

https://doi.org/10.1007/s00066-021-01865-3

The original version of this article unfortunately contained a mistake.

There is a mistake in the legend of Fig. 3. The labelling has been reversed. It should be: Fig. 3 Dose-volume histograms for the thyroid gland in unilaterally $(\mathbf{a} B L U E)$ and bilaterally (b RED) irradiated patients. Instead of: Fig. 3 Dose-volume histograms for the thyroid gland in unilaterally (a red) and bilaterally (b blue) irradiated patients.

The original article has been corrected.
Open Access This article is licensed under a Creative Commons Attribution 4.0 International License, which permits use, sharing, adaptation, distribution and reproduction in any medium or format, as long as you give appropriate credit to the original author(s) and the source, provide a link to the Creative Commons licence, and indicate if changes were made. The images or other third party material in this article are included in the article's Creative Commons licence, unless indicated otherwise in a credit line to the material. If material is not included in the article's Creative Commons licence and your intended use is not permitted by statutory regulation or exceeds the permitted use, you will need to obtain permission directly from the copyright holder. To view a copy of this licence, visit http://creativecommons.org/licenses/by/4. $0 \%$.
The online version of the original article can be found under https://doi.org/10.1007/s00066-021-01865-3

Anastassia Löser, MD

an.loeser@uke.de

1 Outpatient Center of the UKE GmbH, Department of Radiotherapy and Radiation Oncology, University Medical Center Hamburg-Eppendorf, Martinistraße 52, 20246 Hamburg, Germany

2 Institute of Medical Biometry and Epidemiology, University Medical Center Hamburg-Eppendorf, Martinistraße 52, 20246 Hamburg, Germany
3 Center for Internal Medicine, Department of Nephrology, Rheumatology and Endocrinology, University Medical Center Hamburg-Eppendorf, Martinistraße 52, 20246 Hamburg, Germany

4 University Medical Center Hamburg-Eppendorf, University Cancer Center Hamburg (UCCH), Martinistraße 52, 20246 Hamburg, Germany

5 Hermann Holthusen Institute for Radiation Oncology, Asklepios Hospital St. Georg, Lohmühlenstraße 5, 20099 Hamburg, Germany

6 Department of Radiotherapy and Radiation Oncology, University Medical Center Hamburg-Eppendorf, Martinistraße 52, 20246 Hamburg, Germany 